\title{
Impact of process condition on glycerin recovery from spent lye
}

\author{
Obumneme O. Okwonna 1, ${ }^{*}$, Amalate Ann J. Obuebite ${ }^{2}$ and Ipeghan J. Otaraku 1 \\ ${ }^{1}$ Department of Chemical Engineering, University of Port Harcourt, PMB 5323 Port Harcourt, Rivers State, Nigeria. \\ ${ }_{2}^{2}$ Department of Petroleum Engineering, Niger Delta University, PMB 071, Wilberforce Island, Bayelsa State, Nigeria.
}

Global Journal of Engineering and Technology Advances, 2022, 10(03), 001-011

Publication history: Received on 18 January 2022; revised on 27 February 2022; accepted on 01 March 2022

Article DOI: https://doi.org/10.30574/gjeta.2022.10.3.0032

\begin{abstract}
This study investigates the recovery of glycerin from spent soap lye derived from the saponification process using palm oil. At different batches, various quantities of brine solution of $8-15 \% \mathrm{w} / \mathrm{w}$ concentration heated at temperatures of 150 to $190{ }^{\circ} \mathrm{C}$ were used to investigate the effects of these on the process alongside a consideration of the effect of catalysis. The average yield obtained on variation of the brine dosage for the catalyzed and uncatalyzed processes were 60 and $56.88 \%$, respectively; whereas temperature consideration gave average yield of 58.5 and $57.05 \%$, respectively. Results showed that catalysis had a slight impact on the process in terms of yield. In all cases lower quantities of the brine solution gave higher yield of the glycerin whereas at higher temperatures, higher yields were obtained; with the best yield of $63.75 \%$ obtained at $190{ }^{\circ} \mathrm{C}$ with $50 \mathrm{~g}$ of $12 \% \mathrm{w} / \mathrm{w}$ brine solution. $\mathrm{R}^{2}$ values for the models predicting the effect of quantity and temperature on glycerin yield for the catalyzed and uncatalyzed processes were $0.983,0.980$ and 0.961 , 0.957 , respectively showing a high positive correlation between these variables.
\end{abstract}

Keywords: Soap lye; Glycerin; Palm oil; Modeling; Brine solution; Characterization

\section{Introduction}

Palm oil (elaeisquineenis) is grown mostly in Malaysia, India, Indonesia, Nigeria and some other parts of West Africa. According to Rifai et al. [1], Nigeria is responsible for about $2 \%$ of the total world palm oil production, second only to India and Malaysia. It is a 16-carbon chain saturated fatty acid obtained from palm tree. It contains fatty acids such as palmitic acids, stearic acids, oleic acids, linoleic acids, and myristic acids. Studies on production of ethyl ester, fatty acids, soap production with glycerin blend, reduction of fatty acid content through enzy matic remediation among others have been successfully carried out on palm oil [2-5]. Palm oil is also used extensively in soap production with glycerin being formed as a byproduct.

Glycerin is a byproduct of fatty acid, fatty alcohol, and biodiesel processing industries. These processing industries produce about $10 \%$ crude glycerin [1]. It is a colourless, odourless, hygroscopic, soluble and viscous liquid product easily sourced from natural and petrochemical feedstocks. Its molecular formula is $\mathrm{C}_{3} \mathrm{H}_{8} \mathrm{O}_{3}$, hence the presence of the hydroxyl group makes it readily soluble in all proportions of water and alcohol, but insoluble in ether. Other properties are: molecular weight $\left(92.09 \mathrm{gmol}^{-1}\right)$, density $\left(1.261 \mathrm{gcm}^{-3}\right)$, viscosity $\left(1.412 \mathrm{kgms}^{-1}\right)$, refractive index (1.4746), melting point $\left(17.8^{\circ} \mathrm{C}\right)$, and boiling point $\left(290^{\circ} \mathrm{C}\right)[6]$.

Because of its properties, glycerin is a vital component in wine production and other assorted drinks. Its effectiveness as an anti-freeze/ coolant base for heavy engines has been reported [7]. Producing glycerin from palm oil will help reduce wastage from the soap making process thereby increasing revenue generation which will in turn encourage local

\footnotetext{
${ }^{*}$ Corresponding author: Obumneme 0 Okwonna

Department of Chemical Engineering, University of Port Harcourt, PMB 5323 Port Harcourt, Rivers State, Nigeria. 
production. In line with this, studies have been carried out on the characterization of glycerin from multiple seed-oil feedstock, extraction by transesterification, and kinetics of the process among many others [6, 8-10].

Hayyan et al. [11] employed a novel technique to extract glycerin from palm oil while Efeovbokhan et al. [12] investigated the production of glycerin from spent soap lye using palm kernel oil (PKO) and palm oil (PO) for a cold process. Moreover, Isreal et al. [13] evaluated the effect of lye quality and technology on product yield. However, none of these studies considered the effect of other process conditions such as temperature and brine dosage on the glycerin yield. This study seeks to investigate this with a view at obtaining an empirical model for the process.

\section{Materials and methods}

\subsection{Materials}

Palm oil (elaeisquineenis) was obtained from a local mill at Nkpologwu (5 $5^{\circ} 9^{\prime} 0^{\prime \prime} \mathrm{N}, 7^{\circ} 5^{\prime} 0^{\prime \prime} \mathrm{E}$ ) in Aguata LGA, Anambra State. Reagents used were obtained as pure grades, namely: sodium hydroxide pellets ( $96 \%(\mathrm{w} / \mathrm{w})$ ) (from BDH), potassium hydroxide pellets $(85 \% \mathrm{w} / \mathrm{w})$, sulphuric acid from BDH $(98 \%(\mathrm{w} / \mathrm{w}))$, phenolphthalein indicator, brine solution, and distilled water. Equipment include: refrigerator, microwave oven, flat bottom flask, conical flask, measuring cylinder, volumetric flask, stainless steel cup, plastic container, funnel and hand gloves.

\subsection{Method}

The methods adopted for this work include: preparation of solution samples, saponification, and characterization. These methods were carried out in the reaction engineering laboratory of Chemical Engineering laboratory, University of Port Harcourt, Nigeria.

\subsection{Preparation of solutions and sample pretreatment}

Following standard methods and procedures, 0.1 moldm- $3 \mathrm{NaOH}, 0.5$ moldm- $3 \mathrm{KOH}, 0.1$ and 0.50 moldm- $3 \mathrm{H}_{2} \mathrm{SO}_{4}$ were prepared for use at different stages of the work. 8, 10,12, and $15 \% \mathrm{w} / \mathrm{w}$ concentrations of brine solution were also prepared. Furthermore, the palm oil was filtered to remove impurities and its saponification value determined accordingly.

\subsubsection{Saponification process}

$160 \mathrm{~g}$ of palm oil (SAP $=0.201)$ was measured into a $500 \mathrm{~cm}^{3}$ stainless steel container and boiled for $30 \mathrm{~min}$ at a temperature of $60^{\circ} \mathrm{C}$, and allowed to cool to a temperature of $40^{\circ} \mathrm{C}$ under atmospheric condition. $39.7 \mathrm{~g}$ weight of caustic soda/120.30 g of water based on the SAP value was gradually added into the oil amidst vigorous agitation until homogenous slurry was formed. The mixture was heated for $10 \mathrm{~min}$ at $70^{\circ} \mathrm{C}$ using a waterbath making the soap float and was subsequently recovered as the top layer after cooling. The process is shown in Eq. (1)

$$
\begin{array}{lrl}
R-\mathrm{COOCH}_{3} & R-\mathrm{COONa} \mathrm{CH}_{3} \mathrm{OH} \\
R-\mathrm{COOCH}_{3}+3 \mathrm{NaOH} \rightarrow & R-\mathrm{COONa}+\mathrm{CH}_{3} \mathrm{OH} \\
R-\mathrm{COOCH}_{3} & R-\mathrm{COONa} \mathrm{CH}_{3} \mathrm{OH}
\end{array}
$$

\subsubsection{Salting out process}

Brine solution was added into the mixture for soap precipitation, leaving a mixture of glycerin and brine as the bottom products. At each batch, 8, 10, 12 and 15\% w/w conc. of brine solution were used in the salting out process. Furthermore, at different experiments, 50, 80, 100 and $150 \mathrm{~g}$ portions of salt were used to prepare concentrations of the brine solution to study the effect of dosage on the process.

\subsubsection{Glycerin recovery}

The residual soap lye (mixture of glycerin, brine solution, soap particles and impurities) after the salting out process was heated at $60{ }^{\circ} \mathrm{C}$ and filtered into a $250 \mathrm{~cm}^{3}$ conical flask. $0.1 \mathrm{moldm}^{-3} \mathrm{H}_{2} \mathrm{SO}_{4}$ was added alongside 2 drops of phenolphthalein indicator into the mixture in a neutralization reaction process identified by a change in colour. To recover more glycerin, $0.1 \mathrm{moldm}^{-3} \mathrm{NaOH}$ was added to the mixture to get the alkaline medium necessary for glycerin recovery. The glycerin was filtered, weighed and dried of excess moisture.

Similar procedure was followed for glycerin recovery in the uncatalyzed process, although this was done without further acid and alkali treatment. 


\subsubsection{Glycerin concentration}

Concentration of the glycerin samples was done by heating each of the samples in an oven for $1 \mathrm{Hr}$ at temperatures of $150,160,170,180$, and $190^{\circ} \mathrm{C}$ for each batch. This was done in order to study the effect of temperature on this process after which the concentrated samples were decanted, weighed and stored.

\subsubsection{Characterization}

Physicochemical property tests were carried out on the palm oil as well as the products of the study as enumerated:

Determination of saponification value of palm oil

$2 \mathrm{~g}$ of palm oil was added into a $250 \mathrm{~cm}^{3}$ conical flask alongside $25 \mathrm{~cm}^{3}$ of $0.5 \mathrm{moldm}^{-3} \mathrm{KOH}$ amidst vigorous agitation and heated for $1 \mathrm{~h}$. The mixture was titrated against $0.5 \mathrm{moldm}^{-3} \mathrm{H}_{2} \mathrm{SO}_{4}$ using phenolphthalein indicator to obtain the titre value of the excess solution. This process was repeated for 2 extra titre values after which the mean values were obtained and recorded as $V_{1}$.

Similarly, under the same experimental condition, titrating equal volumes of $\mathrm{KOH}$ against $\mathrm{H}_{2} \mathrm{SO}_{4}$ without palm oil (blank solution), the mean titre values were obtained and recorded as $V_{2}$

The saponification value of palm oil was obtained using Eq. (2)

$$
S A P=\frac{\text { molarmassofKOH } * \text { alkaliconc }}{\text { weightofoilsample }}\left(V_{2}-V_{1}\right)
$$

Determination of moisture content of Palm oil

$250 \mathrm{~cm}^{3}$ capacity beaker was cleaned, dried and weighed $\left(W_{1}\right)$ after which $5 \mathrm{ml}$ of palm oil was added into it and weighed $\left(W_{2}\right)$. The sample was heated for $5 \mathrm{~min}$ in a microwave oven operating at $60^{\circ} \mathrm{C}$. It was thereafter placed in a desiccator for cooling and re-weighed $\left(W_{3}\right)$. Eq. (3) was used to obtain the moisture content.

$$
\text { moisturecontent }(\%)=\frac{W_{2}-W_{3}}{\text { weightofoilsample }} \times 100
$$

\subsubsection{Modeling of glycerin Recovery}

The regression equation was used to model the functional relationship between the glycerin yield ( $\mathrm{Y}_{\mathrm{g}}$ ) and quantity of the brine solution used $\left(\mathrm{Bg}_{\mathrm{g}}\right)$. The least square approximation which gave the best fitting for the plot was used to model the process.

\section{Results and discussion}

\subsection{Effect of brine dosage (at different concentrations) on glycerin yield}

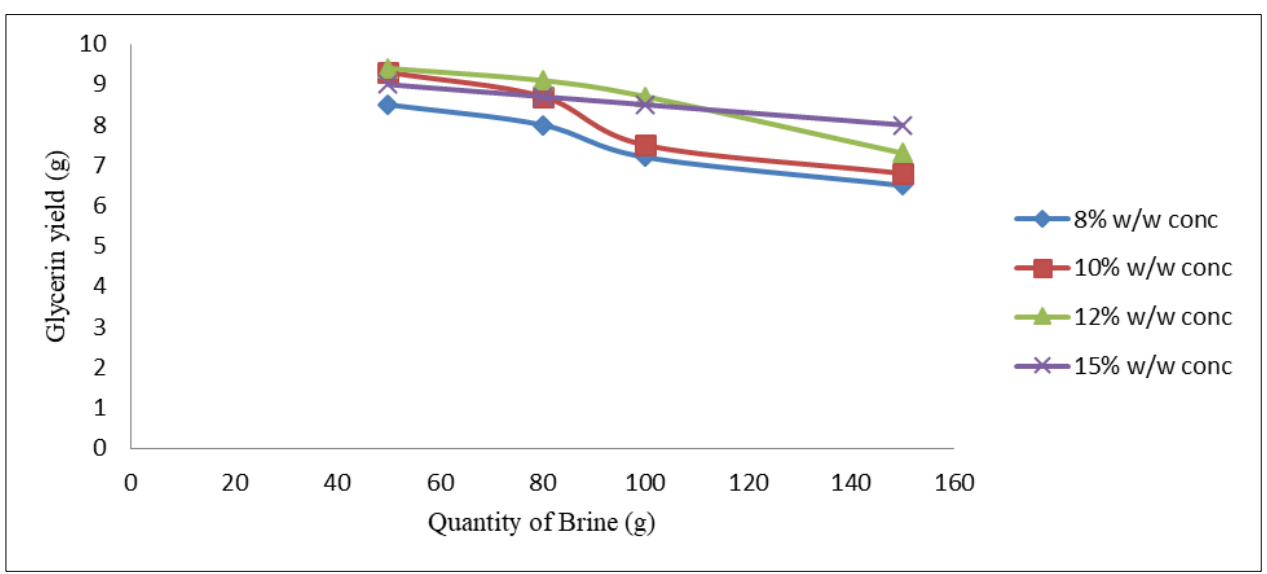

Figure 1 Glycerin yield vs quantity of brine at $150{ }^{\circ} \mathrm{C}$ (catalyzed) 
At constant temperatures, the yield of glycerin using quantities of the brine concentrated at different solutions for the catalyzed and uncatalyzed processes are shown (Figs. 1-10).

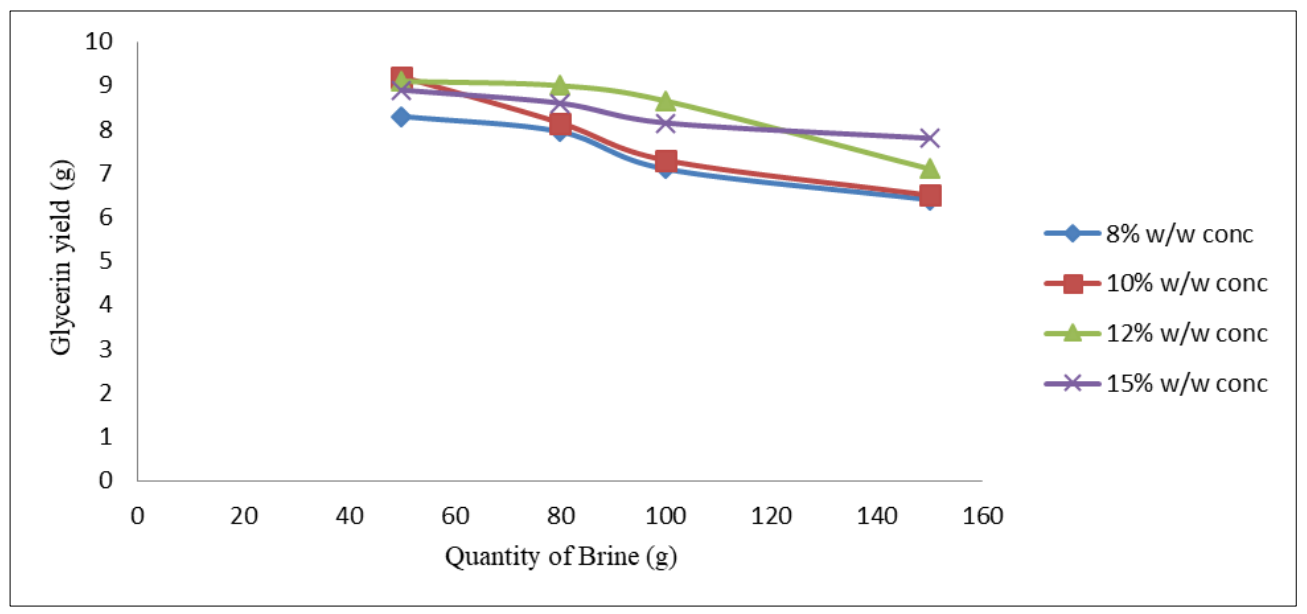

Figure 2 Glycerin yield vs quantity of brine at $150^{\circ} \mathrm{C}$ (uncatalyzed)

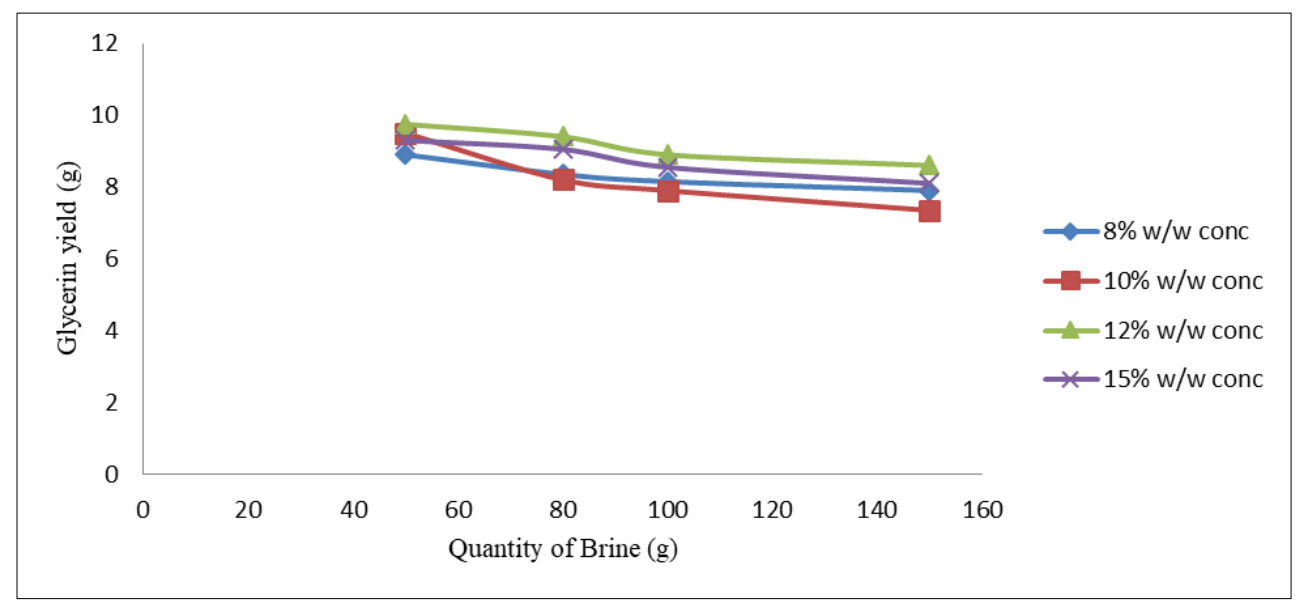

Figure 3 Glycerin yield vs quantity of brine at $160^{\circ} \mathrm{C}$ (catalyzed)

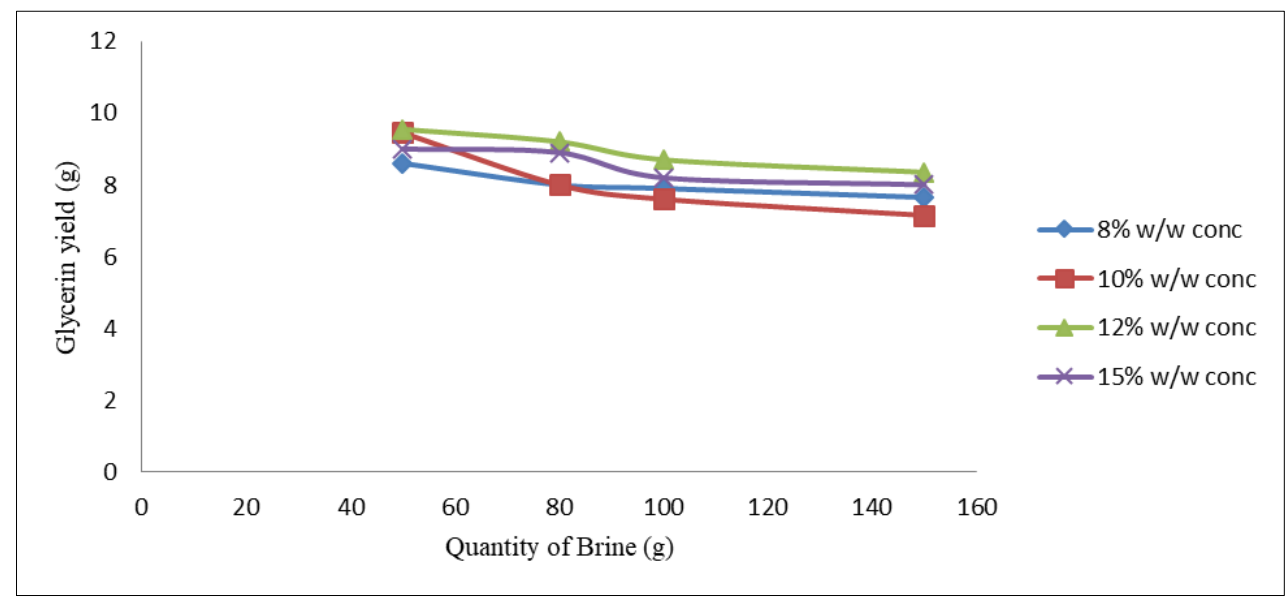

Figure 4 Glycerin yield vs quantity of brine at $160{ }^{\circ} \mathrm{C}$ (uncatalyzed) 
Global Journal of Engineering and Technology Advances, 2022, 10(03), 001-011

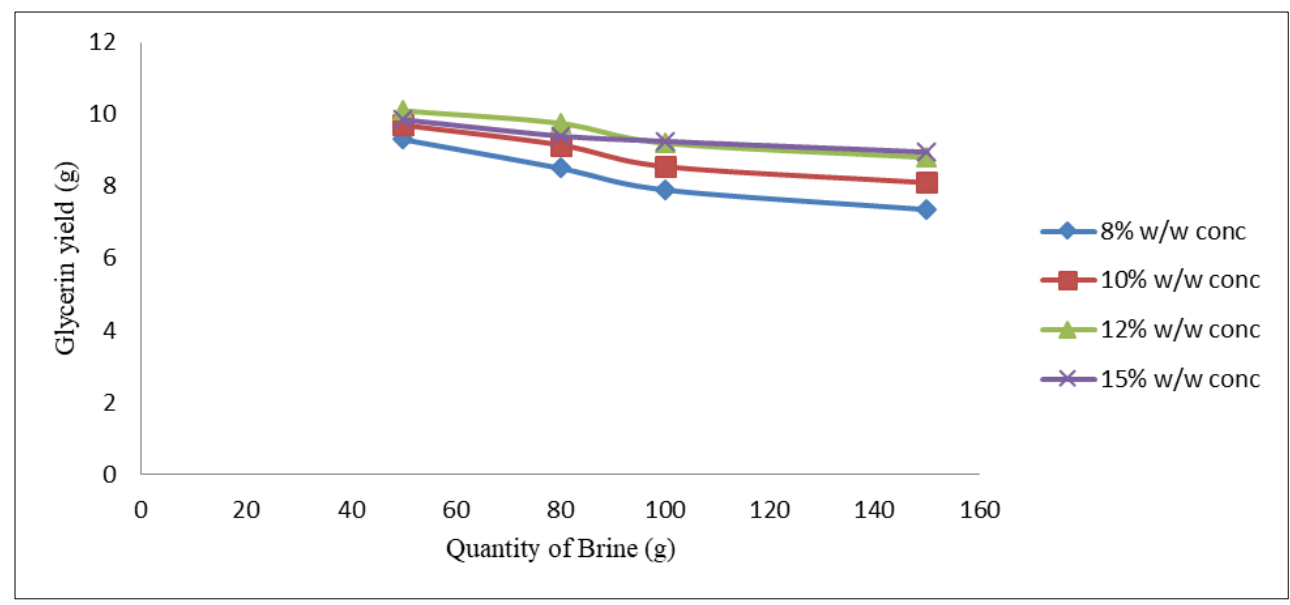

Figure 5 Glycerin yield vs quantity of brine at $170{ }^{\circ} \mathrm{C}$ (catalyzed)

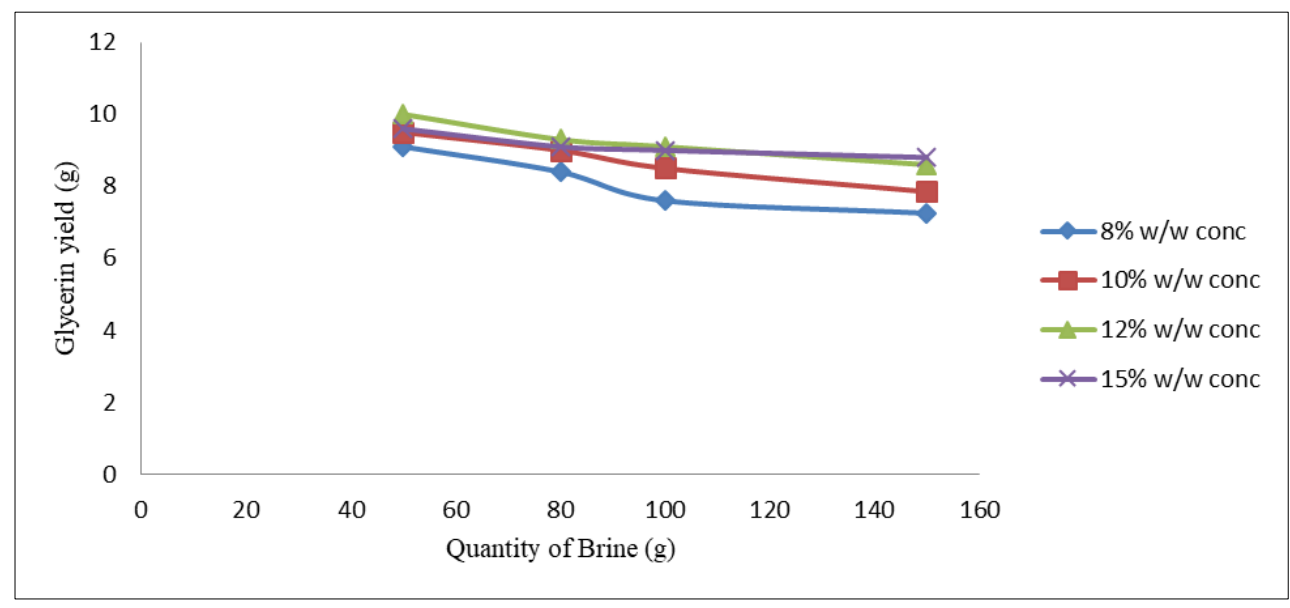

Figure 6 Glycerin yield vs quantity of brine at $170{ }^{\circ} \mathrm{C}$ (uncatalyzed)

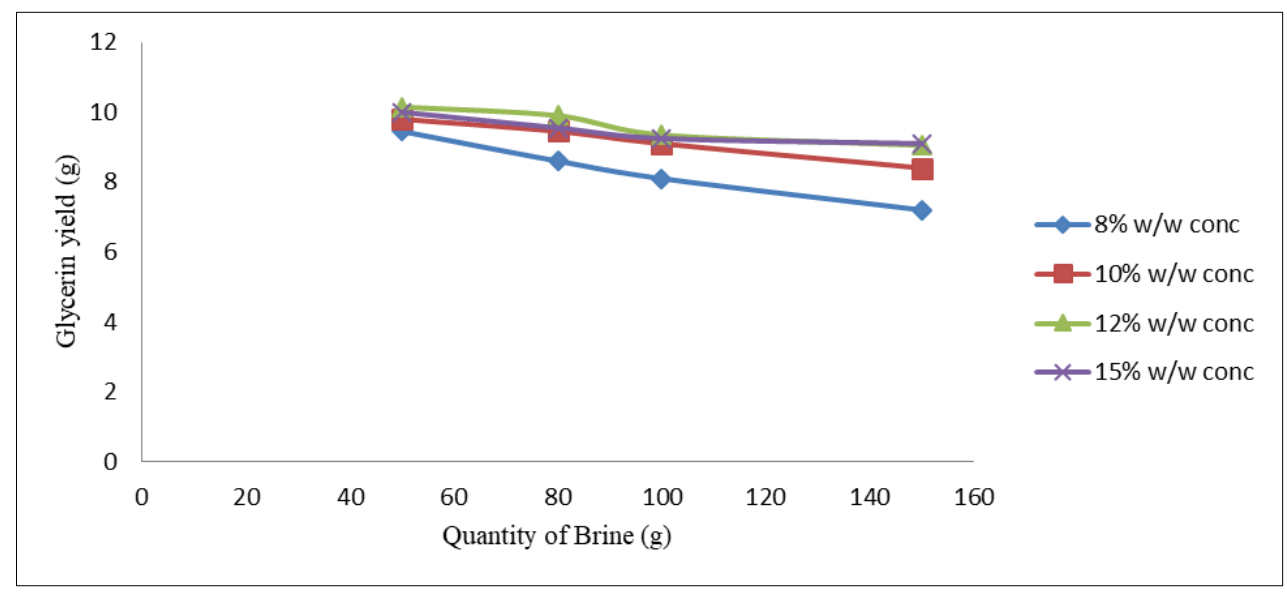

Figure 7 Glycerin yield vs quantity of brine at $180^{\circ} \mathrm{C}$ (catalyzed) 


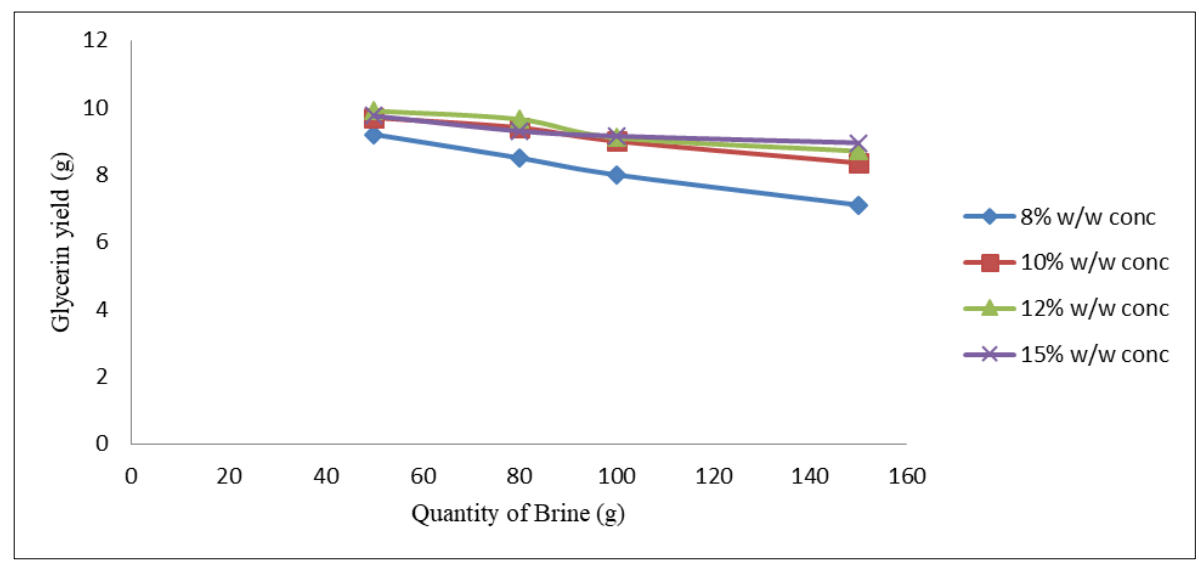

Figure 8 Glycerin yield vs quantity of brine at $180{ }^{\circ} \mathrm{C}$ (uncatalyzed)

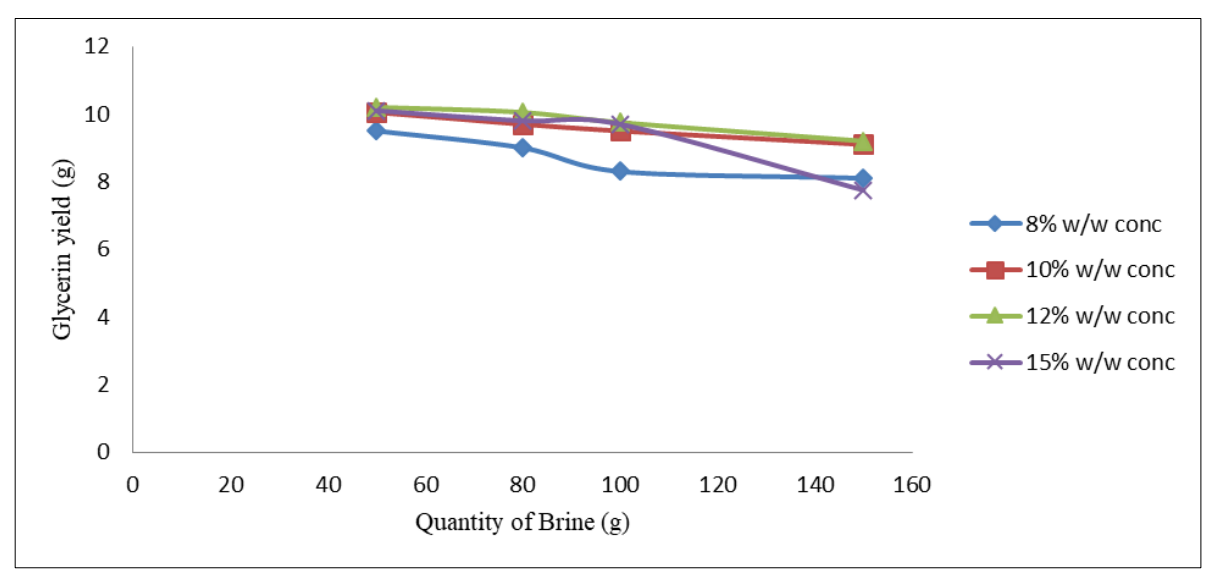

Figure 9 Glycerin yield vs quantity of brine at $190^{\circ} \mathrm{C}$ (catalyzed)

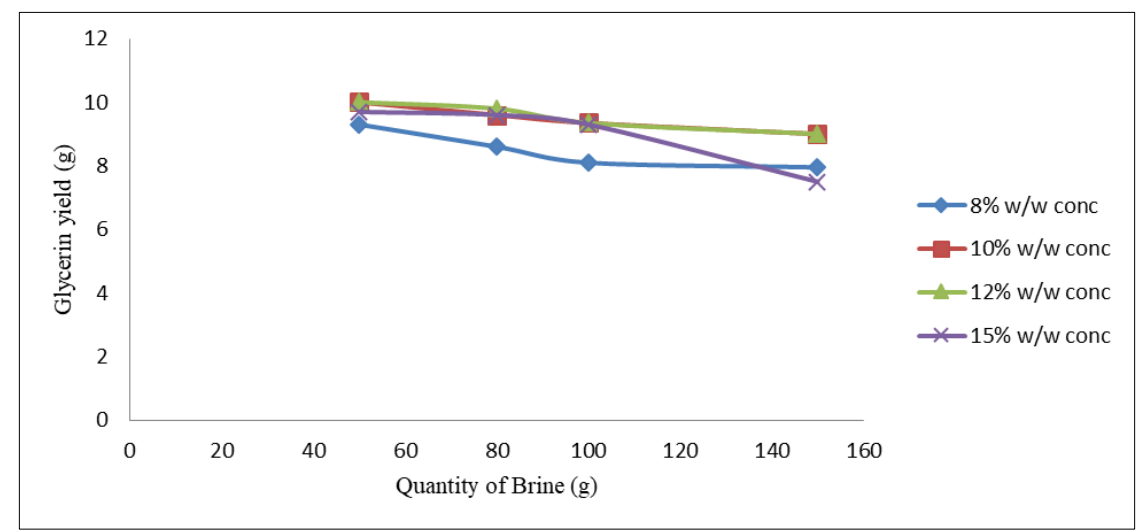

Figure 10 Glycerin yield vs quantity of brine at $190^{\circ} \mathrm{C}$ (uncatalyzed)

A similar pattern was observed for the catalyzed and uncatalyzed solution. Higher yields of glycerin were obtained from lower quantities of the brine and vice versa. This observation corroborates the work of Efeovbokhan et al. [12] using palm oil. The concentration of the solution did not have much impact on the yield, although the $12 \% \mathrm{w} / \mathrm{w}$ solution gave a better yield than others. In addition, higher yields were observed for the catalyzed processes. 


\subsection{Effect of Temperature on glycerin yield}

The effect of temperature on the yield over different concentrations of the brine solution for the catalyzed and uncatalyzed processes is shown (Figs. 11-18)

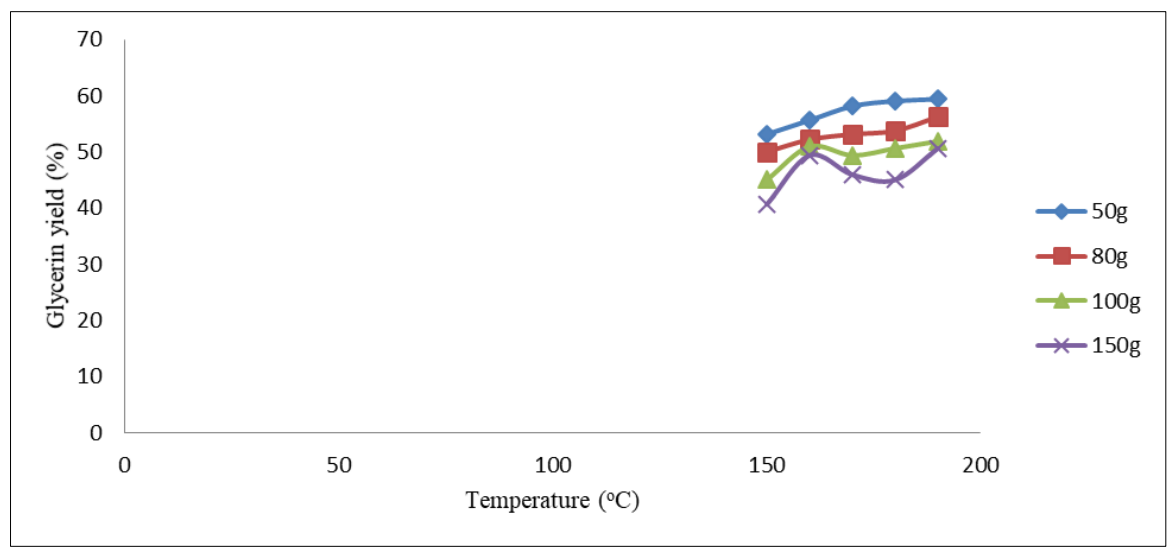

Figure 11 Glycerin yield vs Temp using of $8 \% \mathrm{w} / \mathrm{w}$ brine solution (catalyzed)

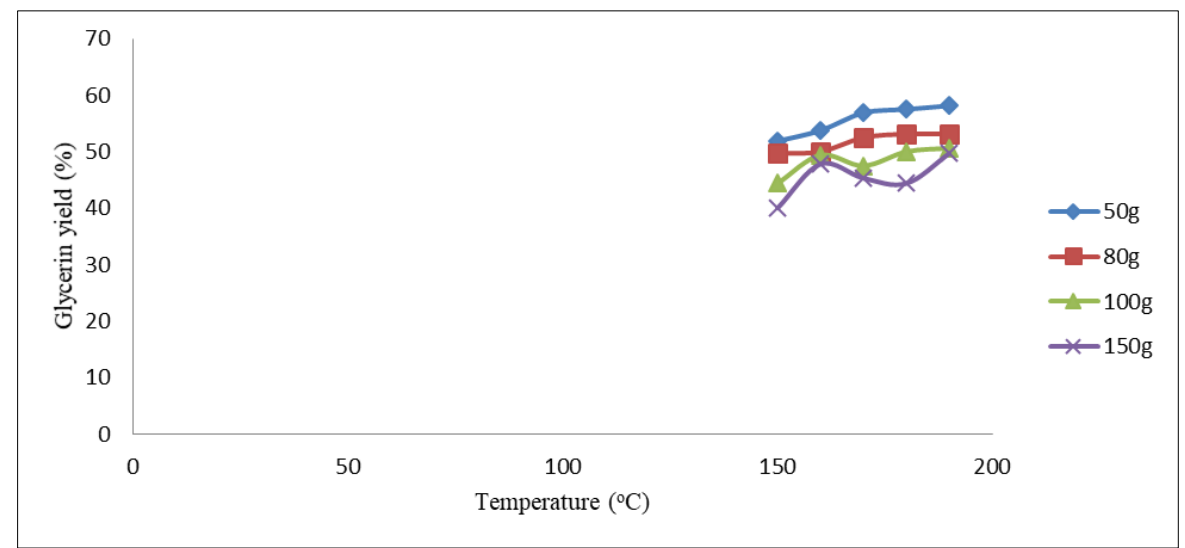

Figure 12Glycerin yield vs Temp using $8 \% \mathrm{w} / \mathrm{w}$ brine solution (uncatalyzed)

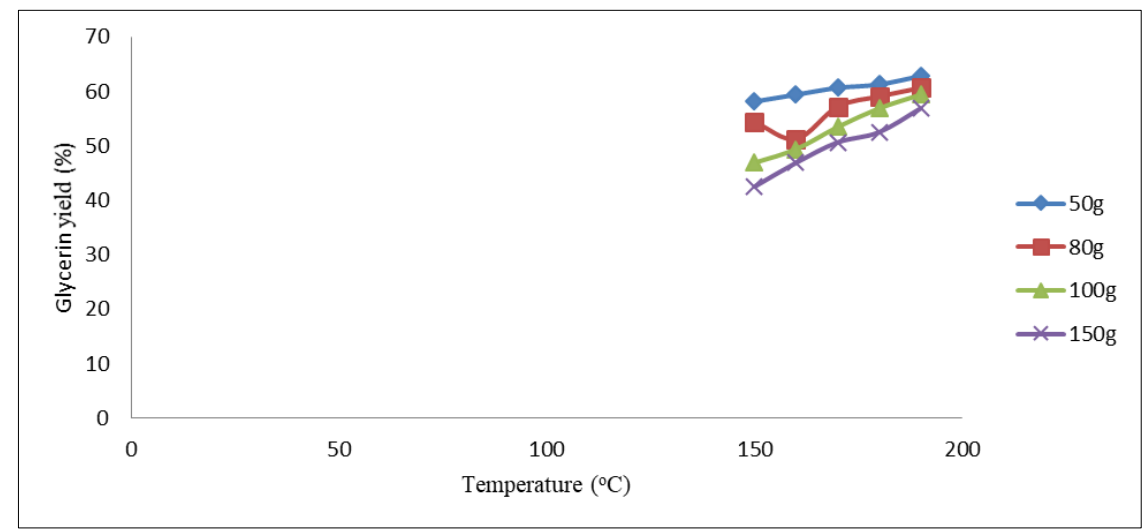

Figure 13 Glycerin yield vs Temp using 10\% w/w brine solution (catalyzed) 
Global Journal of Engineering and Technology Advances, 2022, 10(03), 001-011

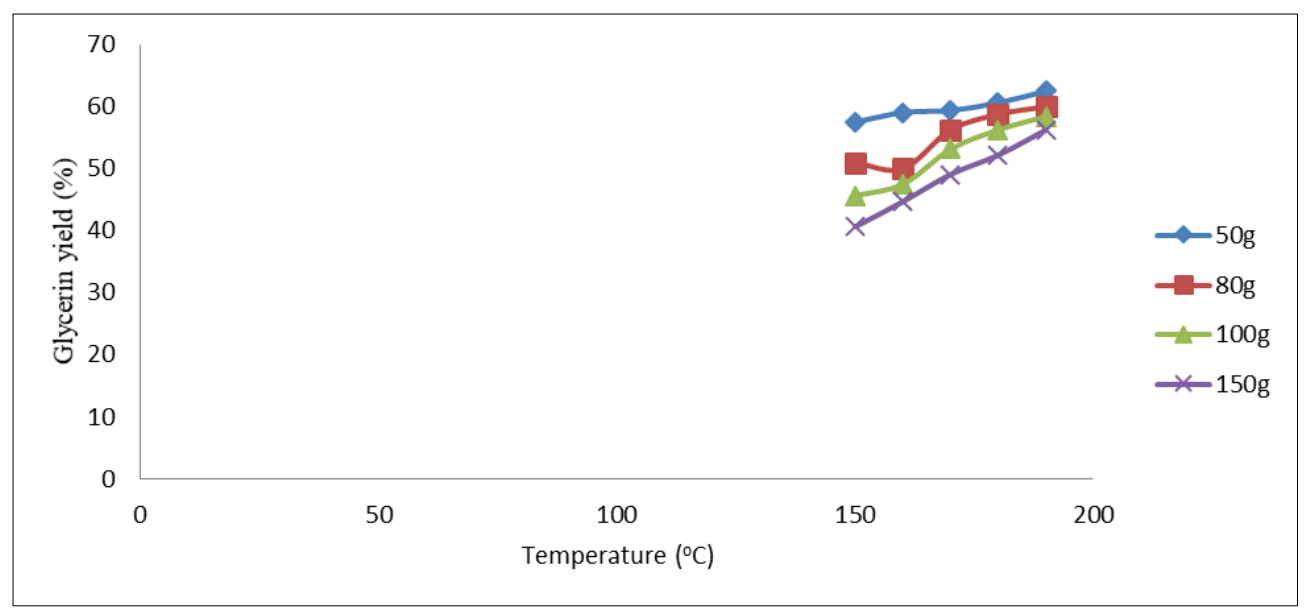

Figure 14 Glycerin yield vs Temp using $10 \% \mathrm{w} / \mathrm{w}$ brine solution (uncatalyzed)

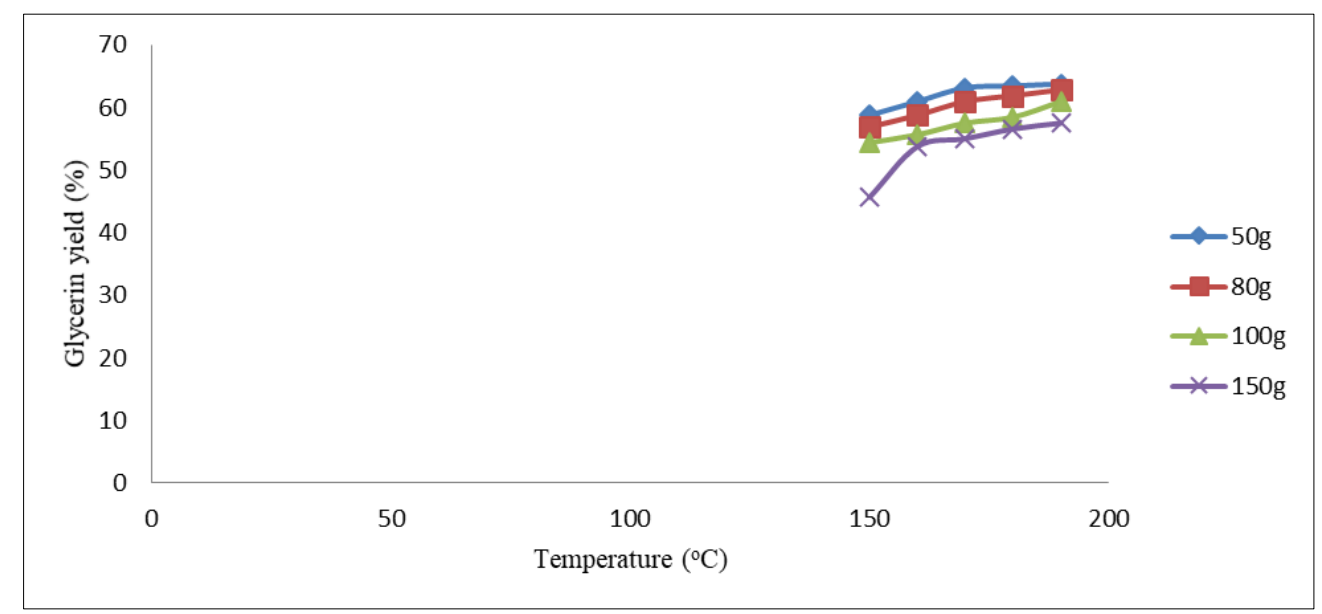

Figure 15 Glycerin yield vs Temp using $12 \% \mathrm{w} / \mathrm{w}$ brine solution (catalyzed)

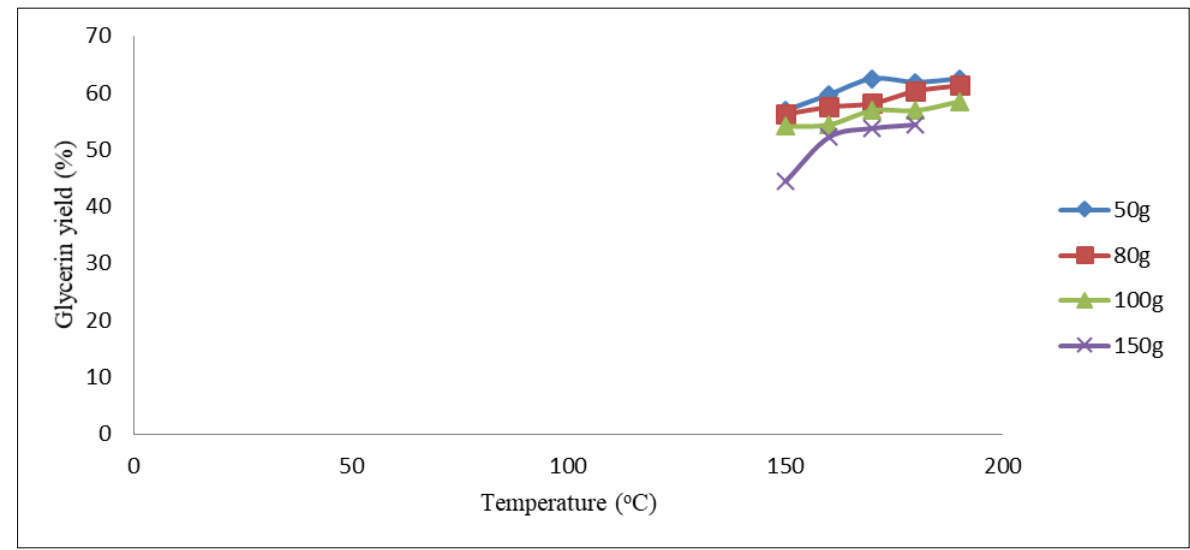

Figure 16 Glycerin yield vs Temp using $12 \%$ w/w brine solution (uncatalyzed) 


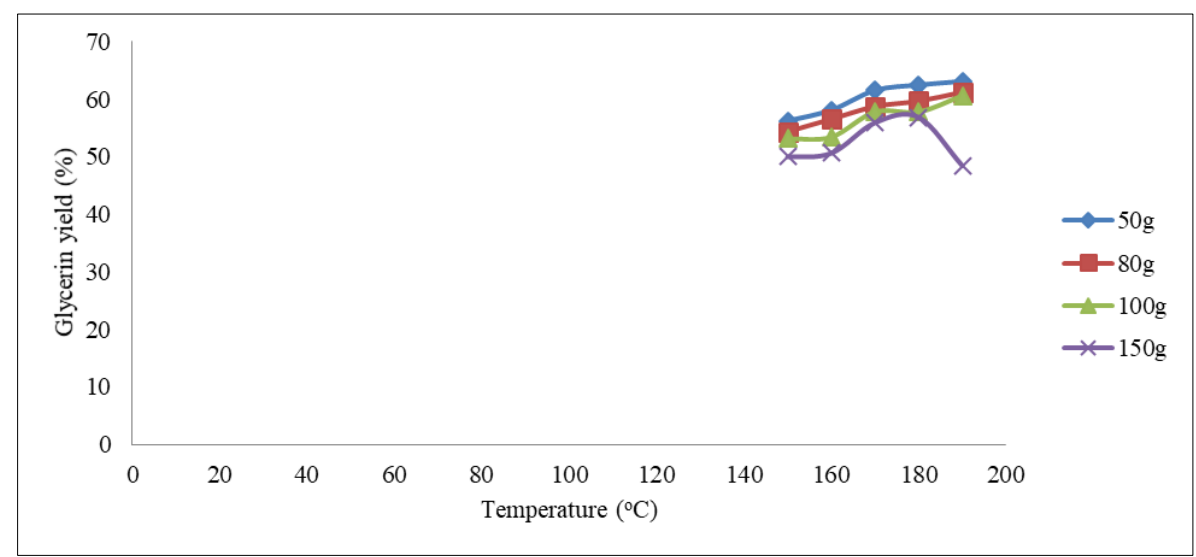

Figure 17 Glycerin yield vs Temp using 15\% w/w brine solution (catalyzed)

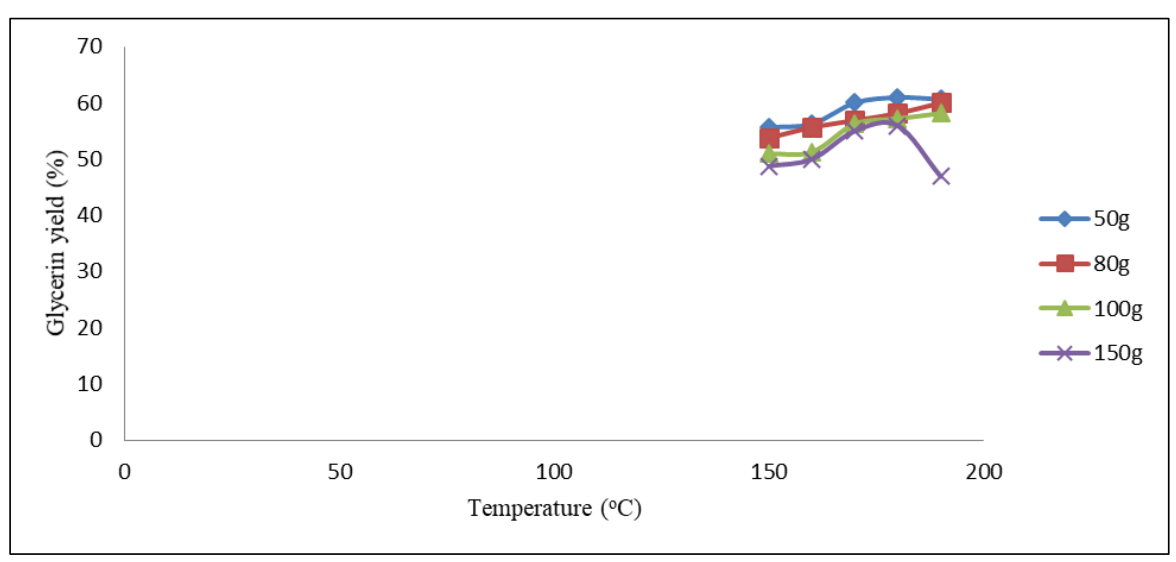

Figure 18 Glycerin yield vs Temp using $15 \% \mathrm{w} / \mathrm{w}$ brine solution (uncatalyzed)

The highest yield $63.75 \%$ was obtained at $190^{\circ} \mathrm{C}$ using $50 \mathrm{~g}$ of brine concentrated at $12 \% \mathrm{w} / \mathrm{w}$. The average yield of glycerin obtained at this temperature were $58.5 \%$ and $57 \%$ for the catalyzed and uncatalyzed samples, respectively showing that catalysis of this process had a slight impact on the product yield. Furthermore, these observations show that higher temperature conditions could be more favorable for this process. This result further confirmed that at higher temperatures, lower dose of the brine would give higher yield of glycerin.

\subsection{Glycerin recovery model}

A plot of the average yield of glycerin for the catalyzed and uncatalyzed processes is shown (Figs. 19 and 20) from where empirical models were obtained for the prediction of yield using different quantities of brine and temperatures.

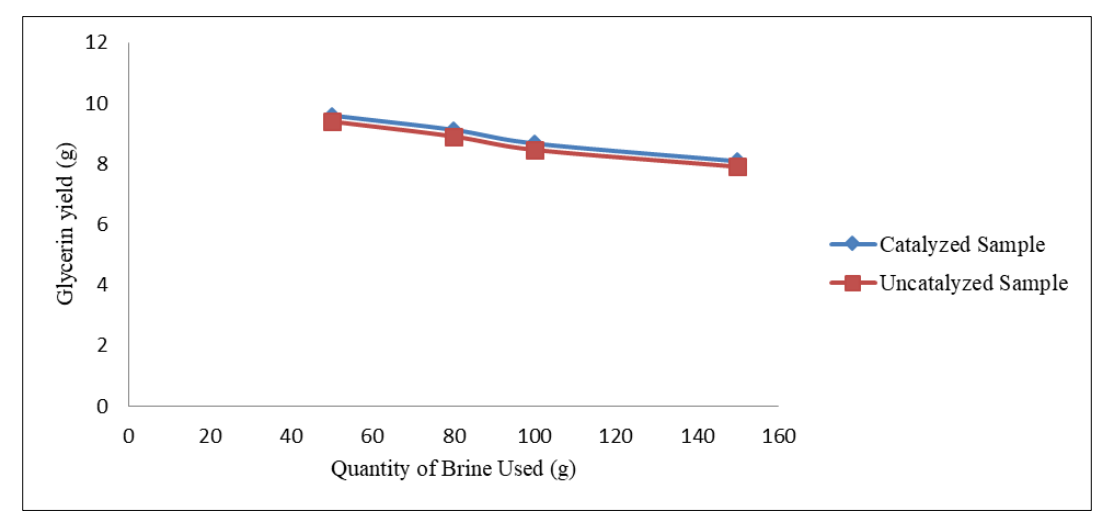

Figure 19 Glycerin yield vs Quantity of Brine solution 


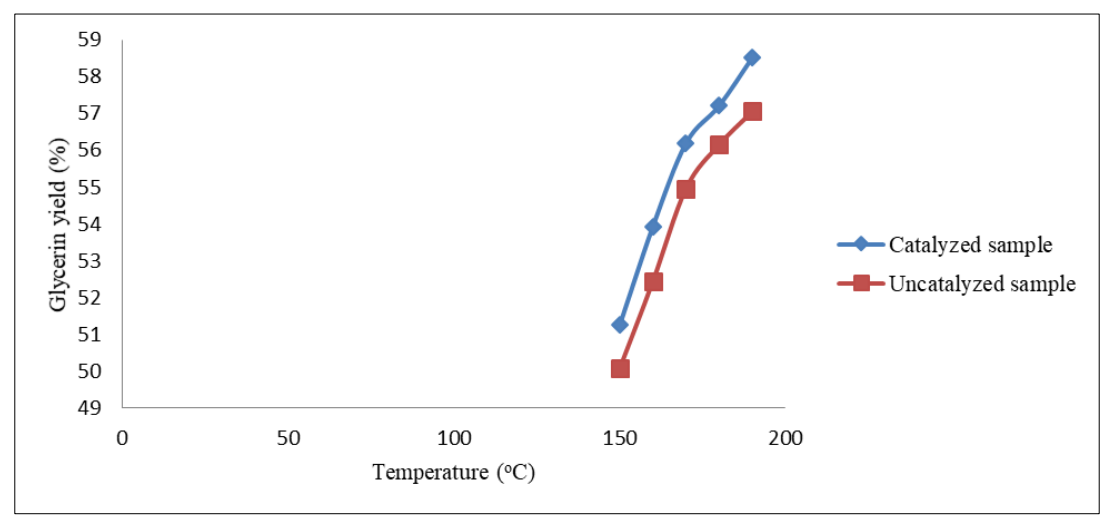

Figure 20 Effect of Temperature on glycerin yield for the catalyzed and uncatalyzed samples

The model for Glycerin yield for the catalyzed and uncatalyzed samples is given by Eq. (4) and (5).

$$
\begin{aligned}
& Y_{g}=-0.015 B_{g}+10.30 \\
& Y_{g}=-0.015 B_{g}+10.08
\end{aligned}
$$

$\mathrm{R}^{2}$ values of 0.983 and 0.980 were obtained for the catalyzed and uncatalyzed samples, respectively. Hence, there is a high positive correlation between the yield of glycerin and the quantity of brine solution used to recover it for both processes.

The model of glycerin yield with temperature for both processes based on the linear function of least square approximation is given in Eq. (6) and (7), respectively.

$$
\begin{aligned}
& Y_{g}=0.178 T_{g}+25.14 \\
& Y_{g}=0.176 T_{g}+24.11
\end{aligned}
$$

$\mathrm{R}^{2}$ values of 0.961 and 0.957 were obtained for both processes, respectively

\section{Conclusion}

Laboratory batch-wise experiment has been successfully carried out to recover glycerin from spent soap lye at different processing conditions. An inverse relationship was observed between glycerin yield and quantity of brine used in the process. Temperature and catalysis had an impact on the product yield. Empirical models developed in this study can be used to effectively predict the process.

\section{Compliance with ethical standards}

\section{Acknowledgments}

The authors are grateful to the Management and Staff of Ballantyne research and analysis resources limited for their technical support.

\section{Disclosure of conflict of interest}

The authors declare that they have no competing interests.

\section{References}

[1] N Rifai, Y Syaukat, H Siregar, G Sa'id. The development and prospect of Indonesian palm oil industry and its derivative products, IOSR J. Economics and Finance (IOSR-JEF). 2014; 4: 27 -39. 
[2] NA Serri, AH Kamarudin, SN Abdul Rahaman. Preliminary studies for production of fatty acids from hydrolysis of cooking palm oil using C. rugosa lipase, Journal of Physical Sci. 2010; 19: 79-88.

[3] K Suppalakpanya, SRatanawilai, R Nikhom, C Tongurai. Production of ethyl ester from crude palm oil by two-step reaction using continuous microwave system, Songklanakarin J. Sci. Tech. 2011; 33: 79-86.

[4] D Cowan, HC Holm, HSYee. Reduction in free fatty acids in crude palm oil by enzymatic remediation, J. oil palm res. 2012; 24: 1492-1496.

[5] MS Tengku, M Mahadhir, T Muhammad, J Mazura, YZ Zaki. Production of eco-friendly soap from glycerin pitch and blend oil, PERINTIS e J. 2017; 7: 83-94.

[6] JC Thompson, BB He. Characterization of crude glycerol from biodiesel production from multiple feedstocks, Applied Engineering in Agric.2006;22:261-265.

[7] RD Hudgens, RD Hercamp, J Francis, DA Nyman, Y Bartoli. An evaluation of glycerin (glycerol) as a heavy duty engine antifreeze/coolant base, SAE technical paper series. 2007; 1-18.

[8] D Darnoko, M Cheryan. Kinetics of palm oil transesterification in a batch reactor, J Amer Oil Chem Soc. 2000; 77: 1263-1267.

[9] SF Cheng, YM Choo, AN Ma, CH Chuah. Kinetics study on transesterification of palm oil, J. oil palm res. 2014; 16: 19-29.

[10] WNRW Isahak, M Ismail, MA Yarmo, JM Jahim, J Salimon. Purification of crude glycerol from transesterification RBD palm oil over homogeneous and heterogeneous catalysts for the bio-lubricant preparation, J. of Applied Sci. 2010; $10: 2590$ - 2595.

[11] M Hayyan, FS Mjalli, AM Hashim, IM AlNashef. A novel technique for separating glycerin from palm oil-based biodiesel using ionic liquids, J. Fuel Processing Tech. 2010; 91: 116-120.

[12] VE Efeovbokhan, PA Anawe, LO Adeeyo, BA Obafunso. Recovery of glycerin from spent palm kernel soap and palm oil soap lye, Int. J. of Eng. \& Tech. (IJET-IJENS). 2012; 12:11-16.

[13] AU Isreal, IB Obot, JE Asuquo. Recovery of glycerol from spent soap lye by - product of soap manufacture, E- J. of Chem. 2008; 5: 940-945. 